DEMOGRAPHIC RESEARCH

VOLUME 30, ARTICLE 66, PAGES 1793-1824

PUBLISHED 6 JUNE 2014

http://www.demographic-research.org/Volumes/Vol30/66/

DOI: 10.4054/DemRes.2014.30.66

Research Article

\title{
Value of Children and the social production of welfare
}

\section{Bernhard Nauck}

This publication is part of the Special Collection on "Theoretical Foundations of the Analysis of Fertility,” organized by Guest Editors Johannes Huinink, Jens Ehrhardt, and Martin Kohli.

\section{(C) 2014 Bernhard Nauck.}

This open-access work is published under the terms of the Creative Commons Attribution NonCommercial License 2.0 Germany, which permits use, reproduction \& distribution in any medium for non-commercial purposes, provided the original author(s) and source are given credit. See http:// creativecommons.org/licenses/by-nc/2.0/de/ 


\section{Table of Contents}

1 The origins 1794

2 The revision 1799

3 Empirical evidence, new developments, and desiderata 1810

$4 \quad$ Acknowledgements 1815

References 1816 


\title{
Value of Children and the social production of welfare
}

\author{
Bernhard Nauck ${ }^{1}$
}

\begin{abstract}
BACKGROUND

The paper describes the origins of the Value of Children (VOC) approach to the cross-cultural research on fertility behavior around the Pacific Rim, and critically discusses its shortcomings at this stage.
\end{abstract}

\section{OBJECTIVE}

The paper then demonstrates how the approach derives its theoretical coherence from the theory of social production functions, making reference to empirical evidence.

\section{RESULTS}

The VOC approach combines a multi-level and action-oriented theoretical model of generative behavior based on the principles of methodological individualism with the welfare maximizing assumptions derived from social production function theory, to create a comprehensive explanatory program.

\section{CONCLUSIONS}

The VOC approach extends economic theories of fertility: Whereas traditional economic theories emphasize the costs of children, the VOC approach also encompasses the supply side of children, i.e., the benefits children bring to their (potential) parents under variable social and economic conditions.

\section{COMMENTS}

The paper outlines future extensions of the VOC approach. The question here is if and to what extent the production of social welfare through parenthood is substitutable by other production modes, and whether children as intermediate goods compete or are complemented by welfare production in other life domains.

\footnotetext{
${ }^{1}$ Department of Sociology, Chemnitz University of Technology, Thueringer Weg 9, D-09107 Chemnitz, Tel. +49 - 371 - 5313 4225. E-Mail: bernhard.nauck@soziologie.tu-chemnitz.de.
} 
The Value of Children (VOC) approach combines a multi-level and action-oriented theoretical model of generative behavior based on the principles of methodological individualism (Coleman 1990) with the welfare maximizing assumptions derived from social production function theory to create a comprehensive explanatory program. The VOC approach nicely complements economic theories of fertility in the tradition of Becker (1960). Whereas traditional economic theories emphasize the costs of children, the VOC approach encompasses also the supply side of children, i.e., the benefits children bring for their (potential) parents under variable social and economic conditions. Thus, the VOC approach offers a coherent and methodologically complete explanation of generative behavior.

\section{The origins}

The concept "Value of Children" (VOC) originates in the work of a task force headed by Fawcett $(1972,1973)$. The main theoretical perspective was developed by task force members Hoffman and Hoffman (1973) in preparation for a larger international research program, designed to find explanations for high fertility rates in many "developing" countries in the context of fertility decline in affluent "western" societies. Both high fertility rates and the related scenarios of overpopulation in some parts of the world, coupled with the prospect of fertility rates dropping below replacement level in other parts of the world (conjuring colorful scenarios of aging and "dying" societies) became hot issues and urgent research topics during that decade. The VOC approach was intended to be a powerful explanatory alternative to the then-dominant economic theories of fertility (Becker 1960, 1976; Easterlin 1968) and to macro-level descriptions of country-specific time series of fertility rates then common in conventional demography. 
Figure 1: The original VOC-Model (simplified)

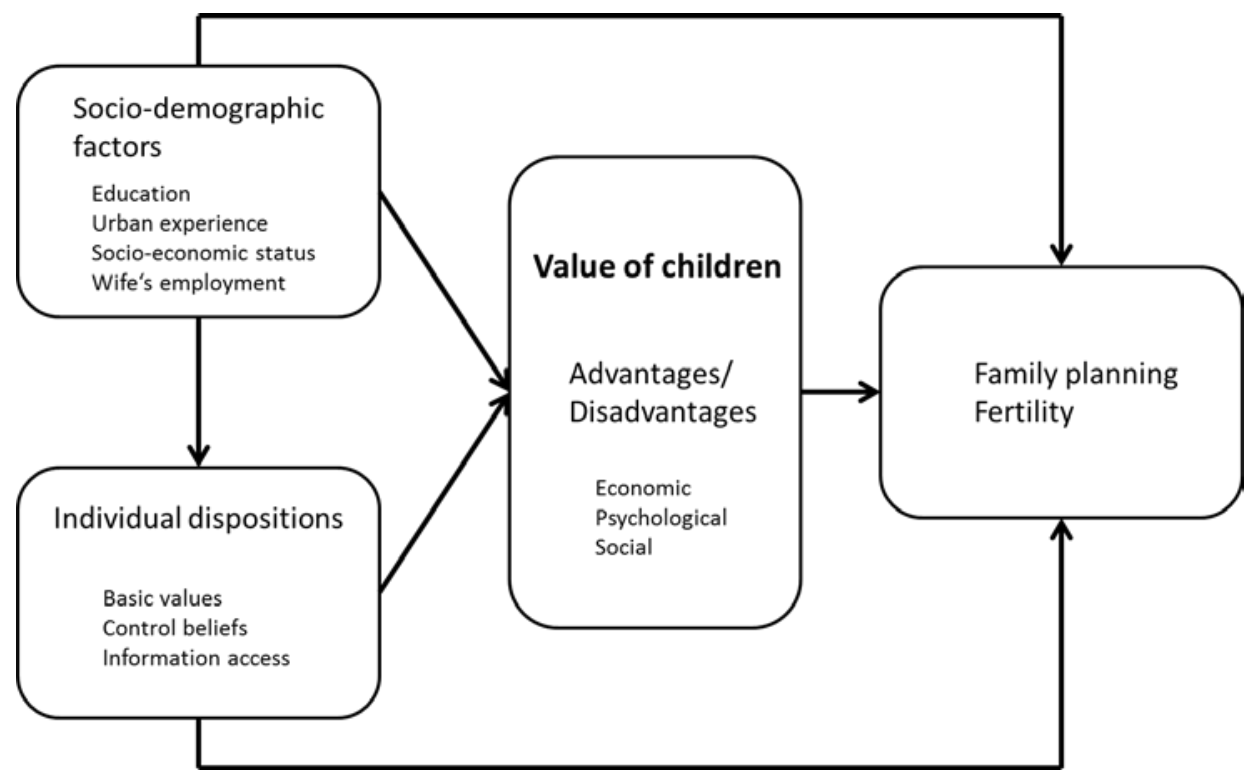

Source: Arnold et al. (1975: 8); Kagitcibasi (1982a: 6)

The VOC approach provided the first systematic explanation for variations in fertility decision-making that explicitly took cultural factors into account. To date it is still the only approach to do so. The starting point of the VOC theoretical model is identical to that of economic approaches to fertility: "objective" economic and socio-structural factors such as economic development, labor market opportunities, and level of education. However, these factors are tied to an implicit decision making model, and the "value of children" is taken as the central mediator variable at the individual level. The value of children is itself subject to variation due to changes in society and culture. Thus, VOC is an important "missing link" between social and cultural conditions, on the one hand, and individual decision making regarding fertility and child-oriented behavior over the life course, on the other (Graph 1). "Value of children refers to the functions they serve or the needs they fulfill for parents" (Hoffman and Hoffman 1973: 20). Obviously, this approach focuses on the value of children for their parents. This starting point takes the basic asymmetry of parent-child relations into account: parents can choose to have children, but children cannot choose to have parents. The initial decision to have children is thus an autonomous decision (independent of the 
influence of children), whereas ensuing decisions in the relationship become increasingly interdependent (based on mutual influence) as the offspring grows older.

Hoffman and Hoffman (1973: 46f) categorized inductively the empirical findings of various sources in order to create an inventory of the various kinds of value children have for their parents. They arrive at the following scheme.

1. Adult status and social identity

2. Expansion of the self, tie to a larger entity, "immortality"

3. Morality: religion, altruism, good for the group, norms regarding sexuality, action on impulse, virtue

4. Primary group ties, affection

5. Stimulation, novelty, fun

6. Achievement, competence, creativity

7. Power, influence, effectiveness

8. Social comparison, competition

9. Economic utility

The nine categories of the value of children are an integral part of a model that also takes several other influential factors into account: alternatives to the value of children, costs of children, barriers, and resources. The central assumption is that the value of children varies from society to society and has far-reaching consequences for generative decisions and the prevalence of parent-child relationship types. Hoffman and Hoffman's (1973) initial model already took into account the possible existence of alternative sources of value for (potential) parents, either individual or institutional. For example, public social-security systems may replace children's economic value. Costs emerge for parents directly as financial and time costs; indirect costs emerge as opportunity costs when abstaining from other goods and activities for the sake of one's children. Barriers are defined as factors that make it more difficult to attain the desired value of children, and these include for example family poverty, inadequate housing, or maternal illness. The model also comprises incentives as factors that encourage parents to pursue and obtain the desired value of children: wealth, good housing, family support, and generally positive attitudes towards children in the social context.

In the 1970s, an empirical analysis of generative behavior in different cultures was undertaken on the basis of the VOC approach. This extensive, cross-national comparative study examined the relationship between culture, socio-ecological context, value of children for parents, and generative behavior (Arnold et al. 1975). The research program included countries of the Far East, but also included Turkey, the United States (Hawaii), and Germany. For each country, systematic variance in opportunity structures (urban and rural) and family resources (social class) was introduced. The surveys for the VOC 
studies were conducted in two phases as pilot and main studies under the supervision of the East-West Population Institute in Honolulu, Hawaii. However, only the monographs for Indonesia (Darroch, Meyer, and Singarimbun 1981) and Turkey (Kagitcibasi 1982a) resulted directly from the main study. The German study used a research design that was only loosely related to that of the main study (Urdze and Rerrich 1981), and the national studies from Taiwan (Wu 1977), Japan (Iritani 1977), the Republic of Korea (Lee 1975), the Philippines (Bulatao 1975), Thailand (Buripakdi 1977), Singapore, and the USA (Arnold and Fawcett 1975) never went beyond the pilot phase.

The theoretical merit of the original VOC approach is that it fulfills the demand for an interdisciplinary, integrative, explanatory concept that combines essential components from different scientific disciplines (Fawcett 1988; Lesthaeghe and Surkyn 1988; Thomson 2001) and, surprisingly, that it anticipated essential elements of multi-level explanatory models in modern social science (Coleman 1990). In particular, it provides all the necessary elements for a methodologically complete action-based theoretical model of generative behavior. The strength of this approach is thus not only its integrative potential but also its combination of individual-actor-based components with structural perspectives on fertility behavior. The approach is thus able to explain intergenerational relationships and fertility behavior in modern, differentiated, affluent societies as well as in segmented, impoverished societies. Thus, its scope of application is very wide, and its power of explanation unusually far-reaching.

Despite its merits, the original VOC approach left some theoretical issues unresolved. For example, the inventories of potential costs and benefits of children show all the signs of empirical inductivism: they emerged inductively from existing empirical research rather than being deductively derived from theory (Friedman, Hechter, and Kanazawa 1994). The value of children therefore remains exogenous and unexplained. Its theoretical status is unclear and it is wholly uncertain whether this list is a complete value system (in the sense of theoretical model building) or whether it may be expanded upon in the future. Attempts to validate the indicators have been successful, albeit only selectively and only in intra-cultural studies. The distinction between economic-utilitarian and psychological-emotional VOC dimensions, in particular, has proven to be theoretically significant (Kagitcibasi 1982b). Economic-utilitarian VOC refers to contributions to the family economy from child labor, household help, and additional income. It also refers to insurance against life risks in old age. Psychological-emotional VOC refers to the strengthening of emotional group ties and to the expressive stimulation through interaction with children. Indeed, most subsequent empirical analyses based on this approach develop their theoretical discussion on the distinction between these two dimensions and their close relationship to high-fertility vs. low-fertility strategies of reproductive behavior. Subsequently, this distinction breaks the path for the development of a comprehensive "model of family change" by Kagitcibasi 
(2007), which had been developed originally for interpreting the Turkish VOC findings (1985).

The empirical merit of the original VOC studies is that they provided the (action-) theoretical "missing link" that helps explain how and why fertility rates are influenced by poverty and affluence on the societal level (Nauck 2005). These studies demonstrated forcibly that high numbers of children are neither the result of "blind" clinging to primordial cultural traditions, nor the result of ignorance regarding effective methods of birth control. Rather, the empirical findings impressively clarified that (potential) parents who have or want many offspring must be in fact pursuing their own "rational" interest within the limits of their individual opportunities and resources. Accordingly, concern about not having enough descendants or about early child mortality is possibly much more widespread than the wish to prevent unwanted pregnancies or additional births (Darroch, Meyer, and Singarimbun 1981). It is thus obvious that one's own children are very efficient, non-substitutable intermediate goods for (potential) parents' welfare production under such societal conditions. It is also evident that in differentiated welfare societies, one's own children are not efficient intermediate goods for welfare production as far as the increase or the maintenance of the parent's physical wellbeing is concerned. Children contribute to the parental household neither through work nor through income in any substantial way. But the efficiency of intergenerational relationships for optimizing emotional benefits, which is also an integral part of parent's welfare production, is extraordinarily high in these societies, especially if the professional lives of (potential) parents are characterized by highly specialized and formalized tasks. Thus, it does not surprise that children's emotional utility dominates the frame of generational behavior and of intergenerational relationships under such societal conditions.

The original VOC studies had several empirical shortcomings. There was no validation, especially across cultures, of central constructs, and empirical measurements left much room for improvement. Empirical findings remained on the level of culture-specific monographs based on descriptive statistics and cross-tabulations. They drew an informative and illustrative picture of variance in VOC in the societies studied, but an attempt to test the underlying hypotheses regarding mediating effects of VOC linking societal conditions and individual resources with fertility outcomes was never undertaken, neither for single cases nor for more challenging multiple cases.

Moreover, the analytical potential of the VOC approach was not fully exploited. The approach does not only encompass fertility behavior; it also has far-reaching implications for intergenerational relationships in general and thus sheds light on parent-child relationships in all stages of the life cycle. Only occasionally have studies of educational attitudes, aims, and practices been undertaken on the basis of the original data (Hoffman 1987; Kagitcibasi 2007: 130) or in ways related to the original approach (Nauck 1989). Theoretical reasoning and empirical research on intergenerational relationships in later 
life stages was never tackled; these might have also included a reversed perspective, i.e. cross-cultural variation in the "value of parents" and its consequences for the character of intergenerational relationships throughout the life course, and for related investments and acquired obligations.

\section{The revision}

One of the main effects of the VOC studies in the 1970s was the diffusion of the empirical indicators they used to mainstream demographic research, especially to studies of "developing" countries such as the Demographic and Health Surveys. This was driven mainly by the open structure of the value inventory, which was interpreted as an invitation to deliberately delete, change, or add empirical indicators. As a result, idiosyncratic and mostly non-comparable empirical findings were generated and interpreted within the framework of the descriptive model of the first demographic transition (Notestein 1945).

In the 1980s and 1990s, sporadic attempts were made to revise and revitalize the VOC approach. Among the most significant was Zelizer's (1994) generic use of the VOC concept to explain societal change in the demand for stepchildren of specific ages and the change in the insurance sum supplied and the compensation granted in case of the death of children of specific ages in the 19th and 20th centuries in the United States. Both are closely related to a switch from economic-utilitarian to psychological-emotional VOC of children during the same historical time period. Another significant attempt at revitalization was made by Friedman, Hechter, and Kanazawa (1994) in their argument that VOC can be used as a one-dimensional concept, claiming that the ultimate reason for the decision to have children is reduction of future uncertainty. Their claim is based on the highly self-binding nature of parenthood and its long shadow over future choices. Although a one-dimensional concept of VOC has several methodological advantages and allows for elegant theoretical modeling, the status of this general proposition is rather unclear. If one follows the arguments of the authors that uncertainty reduction is the ultimate reason for any action taken (Friedman, Hechter, and Kanazawa 1994: 381), then the proposition is true in the sense that any choice taken reduces the number of possible choices and thus may be considered to reduce uncertainty, but then the proposition becomes empirically almost empty. If the reduction of uncertainty through parenthood has a specific meaning, however, then it may have some strength in partially explaining the transition to first-time (!) parenthood, but it does not provide any deductive argument for differences in fertility outcomes or for selective choices such as for male offspring. Nor does the uncertainty-reduction argument deliver reasoning to explain changes in the demand for specific characteristics of the parent-child relationship, i.e. for the specific 
supply of children for their parents, which may then explain differences in the timing of parenthood, in the total number of children, in the number of children of a specific sex, and in parental investments. Moreover, one may argue that this specific proposition is invalid altogether, because parenthood may voluntarily increase uncertainty in some respects. This increase in uncertainty can, in fact, be explained by a revision of the VOC approach, as discussed below.

A major revision of the VOC approach was made in connection with a research program launched in the first decade of the 21st century. This research, again organized by an interdisciplinary team of psychologists and sociologists (Trommsdorff and Nauck 2005; 2010; Trommsdorff, Kim, and Nauck 2005) aimed at a partial replication of the original VOC studies about one generation later, but was intended to go beyond the original studies in three important aspects. It was designed to:

- revise the VOC approach using recent theoretical advances;

- broaden the scope of empirically studied subjects so as to exploit the potential of the VOC approach in a more comprehensive manner;

- test the theoretical assumptions explicitly with appropriate, more advanced techniques of data analysis, especially with regard to cross-cultural comparisons.

The revision aimed at developing explanations for changes and differences in fertility rates and prevalence of types of intergenerational relations, i.e. for explananda on the macro-level, for a better understanding of the systematic relationships between categories of actors and the likelihood of behavioral outcomes (see Figure 2). The prediction of individual action was not intended. Accordingly, behavioral "rationality" -assumptions in the following refer to the matching of incentive structures and behavioral choices; they do not necessarily represent individual (individually calculated) optimizing strategies.

A promising path for the reconceptualization of the VOC approach is its integration within the general theory of social production functions, which would allow VOC to be deduced from a general social theory. Without specifying the potential benefits of having children, any explanation of fertility is incomplete: "To produce useful empirical results, action theorists must be able to specify ex ante the values of the expected outcomes of a set of feasible courses of action.” (Hechter, Kim, and Baer 2005: 91, emphases in the original).

To overcome its theoretical deficiencies, the implicit decision-making model of the VOC approach has been revised and reconceptualized as a special case of the general theory of social production functions (Nauck 2001; 2005; 2007b), assuming that fertility 
and intergenerational relationships are part of human welfare production. "The theory of social production functions states that human beings strive for two major goods: physical wellbeing and social approval. Thus these two goods are the major goals for human beings" (Lindenberg 1996: 169). The basic theoretical idea is that these major goods cannot be produced directly, but are produced by instrumental factors. "The top is formed by a function in which utility (U) is produced by physical wellbeing (PW) and social approval (SW), thus the utility function is $\mathrm{U}=\mathrm{f}$ (PW, SW) (Lindenberg 1996: 174). Physical wellbeing is produced by two means: stimulation and comfort, which are "suggested as the two first order instrumental goods for the production of physical wellbeing" (Lindenberg 1996: 173), and which are neither substitutive nor complementary to each other. "Social approval is produced by three means: status (S), behavioral confirmation (BC) and affection (A). Thus, the production function for social approval is $\mathrm{SW}=\mathrm{f}(\mathrm{S}, \mathrm{BC}, \mathrm{A})$. Each of these factors can, in turn, be an instrumental goal produced by other factors ... The lower we go in the hierarchy, the more context-specific the production function will become” (Lindenberg 1996: 175).

In the text below, the term "social esteem" is used instead of "behavioral confirmation" because it better represents the instrumentality of a production factor without changing the theoretical argument. The equal status of the two basic goals in the theory of social production functions distinguishes it both from most economic theories, which emphasize physical wellbeing alone, and from Maslow's need hierarchy (1954), which plays an important role in the explanation of the second demographic transition (Lesthaeghe 2010). The equal status is justified by arguments from social anthropology on the specifics of the conditio humana (Esser 1993: 149ff): the unique combination of high plasticity and adaptability with the necessity of coorientation and cooperation. Lindenberg specifies that below these first-order means of production lie further layers. Second-order means of production consist of activities and endowments, third-order means of production are those necessary for executing activities and obtaining endowments, and fourth-order means of production are those that can be mobilized when changes in production capacity require a substitution. This hierarchy of production factors has the advantage that it allows for the analysis of substitution processes, if and when contextual conditions or the position in the life course change.

The theory of social production functions is based on two basic assumptions. The greater the expected social approval for any particular action alternative, or the higher the expected increase in physical well-being associated with the action alternative, the more likely this alternative will be chosen. As the actor cannot satisfy both basic needs directly, the various production factors have to be evaluated for their context-specific efficiency. The second assumption is that the efficiency of a production factor in satisfying basic needs within a specific context increases its likelihood of being chosen. The more persistent the efficiency of a production factor in context is, the higher is the 
probability of its intergenerational transmission and of its institutionalization as a routine cultural solution.

The explanatory program for VOC is then to develop a special theory of how and under which conditions children become intermediate goods for their (potential) parents' welfare production through the optimization of parental physical wellbeing and social approval and to specify the position of children within the means of production. Accordingly, the general model of social explanation (Coleman 1990: 11) can be transformed into the special case of the explanation of fertility (Suckow 2008: 109), as displayed in Figure 2.

Figure 2: Basic model of the special action theory

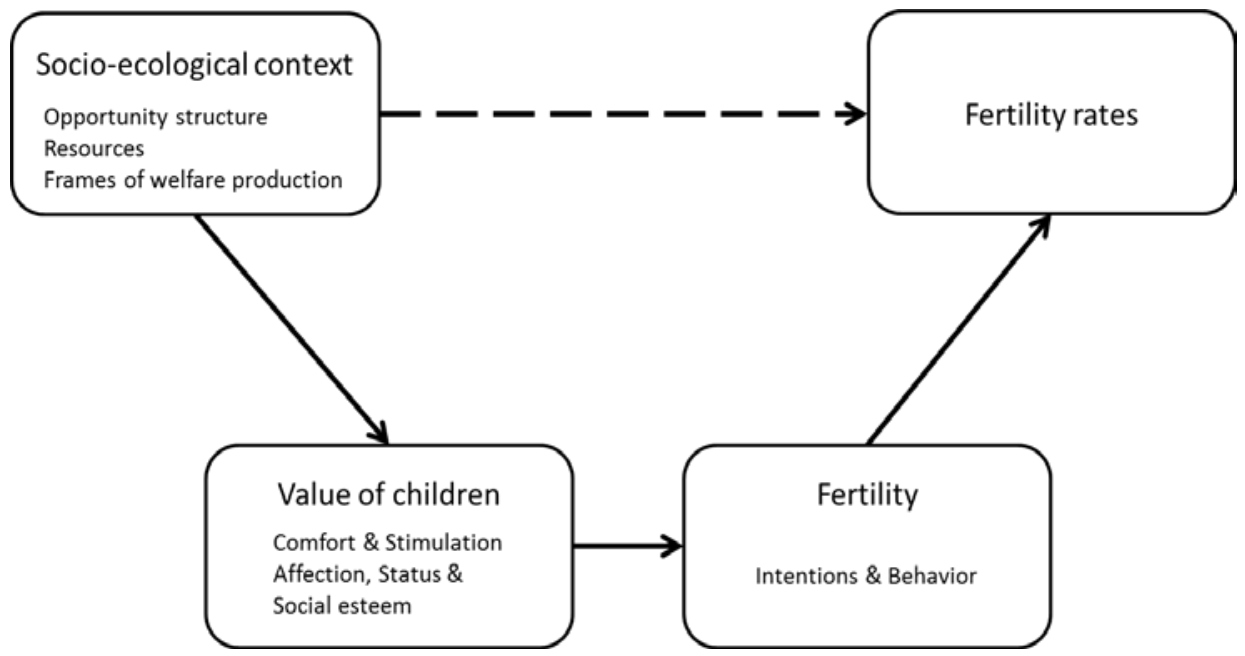

Fertility decisions and the shaping of lifelong parent-child relations are analyzed and explained as an aspect of maximizing subjective utility under specific, perceived conditions. The respective situation of action and socio-cultural "frames" determine the action alternatives available for achieving the actor's goals (Esser 2001:259ff.). They also determine whether and to what extent parenthood is an efficient strategy within these alternatives, and whether children are important intermediate goods such that it is worthwhile bearing them, bringing them up, nurturing them, and investing in them in every other possible way. Accordingly, "cultural” factors enter into this model through the available socially transmitted options (frames), routinized behavior for the optimization in the social production function (habits), and institutional settings. 
Significant short-term, intermediate, and long-term contributions of children to the social production function, including intergenerational relationships over the entire life span, can be distinguished:

- Children help to improve their parents' comfort if they actively contribute to household production and thus function as productive and not just as consumption goods. This can be achieved through their own contributions to welfare production within the parental household as well as by contributing their own income earned on the labor market. It can also be related to the intermediate effect of early assistance in the family household as well as to the long-term effect of contributions to insurance against life risks for the parents. Therefore, children's general utility for optimizing parents' comfort lies in their potential for income/work utility and insurance utility. Children also provide physical and psychological stimulation. This is especially salient in early parent-child interaction, when babies and toddlers need continuous nutrition, care, and observation. Stimulation is thus an immediate result of parenthood. Therefore, children's general utility for optimizing stimulation of their parents lies in their potential to create immediate, typically not substitutable challenges and responsibilities. While stimulation and affection may be analytically differentiated, and while in other life domains stimulation may occur empirically without affection, attachment theory provides sufficient theoretical arguments that stimulation and affection are linked in parent-child relationships (van Ijzendoorn and Sagi 1999). In the case of children in the social production function, one can reasonably expect stimulation and affection to be linked, too. It is obvious that if stimulation through children is highly valued, this does not decrease, but purposively increases uncertainty for potential parents: The stimulation utility of parenthood, which because of its short-term expectation horizon is particularly important for generative decisions, makes it obvious that parenthood is one of the "last adventures" of modern societies. Parenthood decisions have an extraordinarily long shadow for the rest of the life course, and the outcomes are highly uncertain.

- Children can both directly and indirectly optimize their parents' social approval. They contribute indirectly to the social approval of their parents when creating (additional) relationships with others or when intensifying existing relationships and improving their quality. Moreover, children themselves can be a status symbol and, in a specific social context, serve as a positional good that may "produce" social recognition in a very direct way. Typically, this utility of children emerges over the short term. Finally, children improve social 
approval directly. Parenthood creates a "native," close, intimate, emotional, life-long, bonded, and committed social relationship that contributes very directly to self-validation and personal identity formation, and gives meaning and relevance to personality. Intergenerational relationships are based on and largely characterized by dialogical interactions (Huinink 1995). As social approval from significant others becomes more and more specific in functionally differentiated societies, "authentic" intergenerational relationships with their "unlimited time" perspective may increase in importance. Typical for this utility of children is its long-term perspective, although a number of its aspects emerge early on. Therefore, children's general utility for optimizing parents' social approval is their potential for status attainment and for dialogical-emotional utility in the quality of the parent-child relationship itself. This aspect allows one to connect the VOC-approach to models of intergenerational solidarity (Bengtson and Roberts 1991; Bengtson 2001) and to extend it beyond the study of fertility, as it takes the "long shadow" of anticipated future events into account (Klaus and Suckow 2005).

Table 1: Children in the social production of welfare

\begin{tabular}{lll}
\hline & Physical wellbeing & Social approval \\
\hline Short-term & stimulation/affection & status-attainment \\
Intermediate & work utility & social esteem \\
Long-term & insurance utility & dialogical interaction \\
\hline
\end{tabular}

Conceptualizing children's utility as an intermediate good in the social production function integrates the VOC approach into a general social theory and provides a foundation in social anthropology (Esser 1993: 143ff.). This foundation was lacking in the original approach and is necessary especially for cross-cultural explanations of variable substitutes in the pursuit of major goals.

These considerations, derived from the theory of social production functions and empirical arguments developed in the early VOC studies (Kagitcibasi 1982a), also resemble the early basic conceptualizations of economic theories of fertility (Leibenstein 1957; 1974). Interestingly, the original VOC-approach never took notice of Leibenstein or other economic theories of fertility. The similarities are to some extent due to the fact that both economic theories and the VOC approach rely on an implicit model of rational choice in fertility decision making, in which subjectively expected costs of children are weighed against potential benefits. In fact, the economic theory of fertility (Becker 1960) and the VOC approach are each incomplete in themselves, but complement each other 
well. Whereas fertility models derived from economic theory are exclusively driven by price theory (Lesthaghe and Surkyn 1988; Robinson 1997; Braun 2000), inasmuch as they refer only to the individually variable, generally increasing costs of children in affluent societies, models derived from the VOC approach also emphasize the supply side of children, as they refer to the variable benefits of having children in specific social contexts. In fact, this aspect only becomes clear in the context of the theory of social production functions, not in the original formulation of the VOC-approach. In the original, demand for and supply of children are not clearly separated, and in most cases, VOC is solely interpreted as freely chosen motivations for having children, and hence as demand. However, it is emphasized within the theory of social production functions that children are production factors within specific societal contexts, and thus supply goods which are instrumental for the major goals of human beings.

Within this framework, bridging hypotheses are easily generated for the effects of institutional differences at the societal level and of individual opportunity structures and resources (Nauck 2001; 2005; Nauck and Klaus 2007). They will demonstrate the theoretical potential of the VOC approach when embedded in the framework of the theory of social production functions, and when used for explaining context-dependent generative behavior in cross-cultural comparison. Examples of such bridging hypotheses are discussed below, but because of space limitations these examples are selective and more illustrative than systematic.

Since the approach emerged, the most obvious connection exists between VOC and the number of children. If the special case of polygamy is disregarded, family size is influenced only by generative behavior. Whether generative behavior is primarily optimized for work and insurance utility or for emotional and social utility matters. One should expect differences in the number of children with which these utilities can be achieved efficiently (Kagitcibasi 1982a; Nauck 1989; 1997).

- If the work utility of children is high, then it is an efficient strategy to be "rich in children," as each additional child will linearly increase work utility especially in social contexts where the recruitment of workers is limited to kinship members. Each child is an additional source of family income because of his or her (early) work contribution or because each (additional) child distributes the existing workload onto more shoulders. The strategy is restricted by the initial investment costs in children and the available opportunity structures for (early) unqualified labor, largely varying between socio-ecological contexts. As the unit costs of children decrease with their number, the ratio becomes increasingly favorable with increasing dependents. 
- If the insurance utility of children is high, then having many children is also an efficient strategy, as it distributes the burden of supplying the insurance utility for the parents onto more shoulders, and thus reduces each child's duty. Accordingly, if the institutional regime of support for the aged is not based on an indirect "cohort" contract but on a direct "generation" contract, the interest of (potential) parents in having many descendants will increase because having many descendants makes old age support more certain. It will also increase the interest of descendants in having many siblings, as it reduces each child's individual burden.

- If the utility of children for social approval or the creation of additional social relationships is high, having as many children as possible is not an efficient strategy, because the number of additional social relationships will not increase linearly with the number of children. Moreover, the number of additional relationships will reach its saturation point quite early. Accordingly, the cost-benefit ratio is favorable for few children, but unfavorable for childlessness and high parity. It may also be assumed that the stabilization of existing social relationships (especially with the spouse and with the families of origin) will not increase linear-additively, so no additional efficiency gains can be expected in this respect either. No definite solution exists for increasing the social status utility of children, as social status attainment depends directly on social norms in specific contexts. Accordingly, conforming behavior can consist of childlessness, single parenthood, or multiple parenthood; depending on the context. It can be assumed, however, that such norms are strongly related to opportunity structures. It is then probable that social esteem may be increased by having many descendants in those contexts where having many children is an efficient strategy for the increase of physical well-being, too. In the same way, social esteem may be increased through childlessness in those social contexts where childless individuals are at an advantage in the competition for scarce, highly valued goods. Consequently, such norms are primarily an expression of the tradition of efficient, routine solutions in the respective social context in the past, and following them is efficient as long as no salient changes in the opportunity structure occur.

- If the utility of children for dialogical interaction and the emotional utility of having children are high, then it is also inefficient to have many children, as emotional benefits cannot be accumulated in the same way as work or insurance utility. One or two children can provide as much psychological satisfaction as four or more children. At the same time, the absolute (economic and probably 
even psychological) costs increase, so that the ratio is favorable for few descendants but unfavorable for childlessness and high parity. In this respect, a self-enforcing process of fertility reduction may be caused by the fact that children compete in the emotional relationship with their parents. As a result, their interest in (additional) siblings lessens to the extent that new siblings resemble older siblings in characteristics such as age and sex. As the competitive situation will have an effect on the emotional quality of the parent-child relationship, incentives decrease for the parents to optimize emotional benefits by having additional children.

The extended VOC approach is not limited to the explanation of the number of children. In fact, a variety of testable hypotheses can be derived, which may be integrated in future empirical research programs. For example, it is also useful in explaining gender differences in fertility intentions (Diefenbach 2005) and in explaining sex preferences. Strong gender differences and a preference for sons are combined in patrilineal societies with a status-differentiated, sex-specific division of labor, creating differences in the work utility of male and female descendants. Male descendants cannot easily be assigned to do "female" work; i.e., lower-status members are more "flexible" and can be used for a variety of tasks. Accordingly, a one-sided concentration on male descendants would in no way be an optimal strategy. Instead, strong incentives exist to immediately replace female descendants when they marry and leave the household, for example by bringing in new daughters-in-law. This, in turn, contributes to an early, standardized marriage process in patrilineal societies. Parents in patrilineal societies, who (may have no choice but to) optimize the labor utility of children, are thus always interested in the marriage of their sons, as this inserts another welcomed worker into the family economy. The marriage of a daughter, however, is not welcomed at all - and may be blocked - if she is the only child or the last in a line of female descendants. Sex preferences are even more pronounced in the case of the income utility of children. The income utility of male descendants is not only more "certain," and lasts longer, but it is also normally higher because of the combination of human capital investments and time spent on the labor market. All this will increase the male-sex preference in patrilineal societies when shifting from subsistence economies to functionally differentiated market economies.

No special incentives for a gender-specific differentiation of the work and income utility of children, or for a gender-specific differentiation of control interests of parents, are to be expected for societies with an affinal regime. But as the loyalty of children is predominantly based on intergenerational emotional bonds, the work utility of female descendants may be more "certain," and - because of the sex-specific inequality in the survival probability - the control interests of mothers may be more pronounced than those of fathers. Different gender-specific lengths of stay in the community of descent 
result in gender-specific optimization strategies for the insurance utility of children. In patrilineal societies, male descendants belong to the community of descent for their entire life. At the same time, descendants of the opposite sex will not in the long run contribute to the parents' insurance against life's risks because they typically leave the community of descent with their marriage. They thus potentially increase work and income utilities only until their marriage into another lineage. The insurance utility provides no incentive to invest in their human capital. This differing investment, in turn, contributes to the adjustment of gender-specific status differentiation. If the insurance utility is high in patrilineal societies, this will lead to a strong preference for male descendants. As the marriage process of female descendants in patrilineal societies starts relatively early and comes to an end early, this favors marked age differences between spouses. Given higher female life expectancy, wives have a much higher survival probability. Accordingly, the interest in the insurance utility of (male) descendants is more probable in (patrilineal) societies with a descent regime as compared to affinal societies.

In general, girls and boys are - for both parents - a source of emotional satisfaction to the same extent, but societies with affinal and descent regimes differ in their opportunity structures for dialogical interaction. The stronger the sex segregation is in a society, the less emotional satisfaction can be derived from children of both sexes. In societies with a descent regime, the preferences of parents are directed towards the descendants of the same sex because of gender-related status differentiation and sex segregation. Accordingly, fathers will prefer sons and mothers will prefer daughters as a source of emotional satisfaction. The "certainty" of this utility is, however, gender-differentiated. While the father's relationship with their son will likely last a lifetime, the change of a daughter to another lineage is an important factor of uncertainty. In societies with an affinal regime with its bi-linear organization of descent, strong incentives for parents exist for a "complete" reproduction. On the base of these utility expectations, the "ideal" family will be comprised of a "complete" role set of mother, father, daughter, and son. It is, however, possible that this is combined with a slight preference for daughters, as these maintain family relationships and thus provide in the long run more certain dialogical benefits.

Perhaps less obvious is the link between VOC and the institutionalized exclusivity of the family group. The extent to which the family in a society is institutionalized as an exclusive, self-regulated group, specialized on affective relationships, with distinct borders in regard to membership, has consequences for the efficiency of children as intermediate goods in the social production function (Nauck 2005: 196). The more specialized the family in any given society is, the more exclusive is the family and the higher are the restrictions on parents for optimizing their income, insurance, and status-attainment utilities with children. However, emotional utility is not affected by this specialization and correspondingly becomes more "salient." The less exclusive the 
family group is in the respective society, the more internal and external resources of the family are pooled and used reciprocally. This creates incentives in the employment sector to rely preferably on members of the kinship system; the work utility of children is increased. As kinship-based and occupational control rights coincide, this increases the efficiency of employment, as long as work effectiveness is primarily increased by loyalty, and not by specialized knowledge and skills. Low exclusivity of the family group accordingly creates good conditions for the effective use of child labor (and nepotism, patronage, and clientelism).

The higher the exclusivity of the family group in a society, the greater the extent to which social esteem is optimized mainly through primary relationships themselves and not through the appraisal of high-status members of the community (of descent). As a result, no incentives exist for parents to increase their social recognition through the "public" visibility of children. The lower the exclusivity of the family group, the more the parents' social recognition is increased through investments in children, i.e., the occupational or marriage mobility of their children directly increases the parents' social esteem. The higher the exclusivity of the family group in a society, the greater the specialization on the dialogical interaction with children and the greater the personalization of the relationship between parents and children. Accordingly, this utility increases in importance with the strength of the structural differences between the family group and the parents' other fields of action. When these structural differences are small, children compete with other personalized relationships, which lowers their specific utility and increases the opportunity costs of parenthood. Therefore, it is to be expected that the incentive for parenthood is smaller for "social" professions with complex interpersonal relationships than for professions with specific, formalized tasks. The fewer alternatives there are to parenthood for securing strong, personal relationships, the stronger are the incentives to draw emotional utility from parenthood. Lindenberg (1991: 47) has pointed out an additional substitution effect with regard to the affection benefits of parenthood, namely the increasing social homogamy within partnership with regard to (higher) education, which increases the likelihood of closer contact: "the affective relationship between husband and wife, if it develops, will reduce the importance of children for the production of affect," and the more likely it becomes "that they will have fewer children”.

These examples demonstrate the considerable potential of the extended VOC approach for theoretical integration and for relating the explanation of fertility to other phenomena (Nauck 2007a), such as variation in parental investments in offspring, educational goals and socialization practices, individual strategies of work-life balance, the emergence of inelastic marriage markets, the institutionalization of transactions between kinship systems (such as bridewealth and dowry, or homogamy and hypergamy), or the transactions between generations in later life (including inheritance 
systems). It also provides arguments for explaining the timing and spacing of births in the life course of potential parents.

\section{Empirical evidence, new developments, and desiderata}

Empirical evidence for the validity and fruitfulness of the explanatory approach can be drawn from a variety of studies, including those of the original VOC project, but not yet in a comprehensive way. A first source of empirical evidence are studies that use empirical indicators in the tradition of the original VOC studies in fertility surveys especially for the explanation of the demographic transition in developing countries. Although such studies exist in abundance, they have in common that they use various VOC indicators primarily for descriptive purposes in showing attitude differences between societies, or social categories within societies, for which thereafter highly aggregated measurements of fertility outcomes are provided. Such attempts fail to test theoretical assumptions related to the extended VOC approach, which places utility expectations at the individual level as a "missing link" between social context and fertility behavior.

One comprehensive project has been undertaken with the goal of testing rigorously the assumptions of the revised VOC approach. In a multi-country research program, data were collected from "young" mothers whose oldest child was no older than 3 years, and who faced the decision of whether to have another child or not. Data were also collected from "older" mothers with teenagers, from these teenagers, and from the maternal grandmothers of these teenagers. Data collection took place in South Korea, Mainland China and Taiwan, North and South India, Indonesia, Israel, Palestine, Turkey, South Africa, Ghana, Nigeria, Russia, Estonia, Lithuania, Poland, Czech Republic, Germany, France, the United States, and Jamaica. The research program resulted in a series of publications that focused on testing VOC assumptions at two levels.

A first series of empirical analyses tested the relationship between VOC and intra-societal variations in fertility behavior in various countries, allowing variance in welfare levels and the level of institutionalization of kinship and family systems. Publications in this vein included Turkey (Klaus 2008; 2010; Kagitcibasi and Ataca 2005), Israel and Palestine (Suckow 2005; 2007; 2008), Indonesia (Rudolf 2010), Germany (Klaus, Nauck, and Klein 2005), the Czech Republic (Mares and Mozny 2005), South Korea (Kim and Park 2005), and China (Zheng, Shi, and Tang 2005).

A second series of analyses was dedicated to cross-societal comparisons of VOC and fertility, allowing variance in: individual resources, contextual opportunities, adolescents' fertility intentions (Mayer 2009; Mayer and Trommsdorff 2010), fertility strategies between generations (Nauck 2006; 2010a), and fertility outcomes (Nauck 
2007b; 2014a; Nauck and Klaus 2007; Klaus, Suckow, and Nauck 2007; Klaus, Suckow, and Soloveva 2009).

A third series of analyses aimed at integrating VOC-related theoretical assumptions to domains other than fertility, such as parenting (Mayer et al. 2005; Schwarz, Schäfermeister, and Trommsdorff 2005; Albert, Trommsdorff, and Mishra 2007), intergenerational relationships (Kagitcibasi, Ataca, and Diri 2010; Nauck 2009; 2014b; Nauck and Arránz Becker 2013; Schwarz 2010; Schwarz et al. 2005; 2006; 2009; 2010; Steinbach 2008; Trommsdorff and Mayer 2012), and inheritance patterns (Nauck 2010b). The results of these analyses showed that the respective VOC are not only predictive for fertility intentions and outcomes, but also for intergenerational relationships in various stages of the life course.

In terms of the relationship between socio-cultural conditions, VOC, fertility strategies, and fertility outcomes, the general trend of the empirical results forcibly points in the theoretically expected direction, showing clear connections between the respective context opportunities and individual alternatives to welfare production on the one hand, and VOC on the other hand. VOC and fertility are also clearly connected, even when societal factors are controlled for in multi-level models (Nauck 2007b; 2014a). However, effect sizes remained in many cases lower than expected, which suggests that the theoretical framework is satisfactory but that measurement instruments need to be improved. Nonetheless, cross-cultural equivalence has been demonstrated, and reliability indicators show very satisfactory results across societies and generations (Nauck and Klaus 2007; Nauck 2014b).

The empirical results also revealed another unexpected finding: "country" effects on fertility do not disappear even when controlling for context opportunities, individual resources, and VOC (Nauck 2007b; 2014a). This contradicts both the economic theory of fertility and the revised VOC approach. Both approaches share a "rational" decisionmaking model, which in the case of the VOC approach is based on the assumption of individual welfare production. If one or both approaches fit well with empirical reality, then fertility decisions should be directly related to an individual's cost-benefit structure as defined by resources, opportunities, and alternatives. Consequently, if opportunities and individual alternatives are controlled for, no differences in fertility should occur, i.e. "cultural" differences between the respective societies in cross-cultural comparison should vanish and "path dependencies" of culture-specific traditions should not exist.

Future theoretical improvements of the VOC approach should thus account for a specification of the conditions under which the rational decision making model applies, i.e. what is needed is a precise rule for explaining and predicting when an actor chooses to base his or her action on rational choices instead of culture-specific tradition (Esser 2004). In a first attempt, this problem was resolved through the application of complementary framing theory (Esser 2001: 268ff.; Kroneberg 2011: 119ff.), which 
argues that rational-choice decision making is a mode ("reflective-calculating" = rc-mode) that occurs only under specific conditions, whereas the alternate mode of "conventional" or "spontaneous" decisions ("automatic-spontaneous" = as-mode) is prevalent when decisions are so strictly framed culturally that further individual reasoning seems superficial and "un-economic" (Kroneberg 2005: 347). Accordingly, the theoretical revision of the VOC approach needed to specify the social conditions under which "rational" cost-benefit calculations regarding children become prevalent. This should be the case, in new situations, when the expected costs of action alternatives are perceived as high and, consequently, the risk of wrong decisions increases. Such reasoning must also take the specific conditions of fertility decisions into account (Nauck 2007b; 2014a).

On the one hand, on the individual level, the decision for parenthood implies a rather rare "high-gain-high-cost-high-risk" decision in the life course. On the other hand, on the societal level, decisions for parenthood are still rather widespread and common, which makes them prone to institutional regulations. The high gains of parenthood are to be seen in the multi-functionality ("diffuseness") of intergenerational relationships. The high costs, however, are related to the increasingly high investments into the offspring coupled with an extreme uncertainty about the returns, because most of the outcomes except for stimulation and affection - are secured rather late. Both aspects make it most likely that fertility behavior is typically strongly culturally framed and may additionally be regulated by social norms. In this case, individual decisions are most often conventional and not calculated in terms of individual costs and benefits - the "spontaneous" mode in the framing model. Accordingly, variations across societies should be more extensive than variations within, and changes across generations should be slow and relatively "inelastic" (i.e., not immediately responsive to contextual changes). The "rational" mode becomes prevalent only under specific conditions, such as times of rapid social change, extensive intergenerational mobility both spatially and social-structurally, or in the context of heterogeneous social networks (Bühler 2004; Nauck 2007b: 628).

Future directions of improvements in theoretical reasoning of the extended VOC-approach should consider new developments in modeling parenthood as part of goal-related self-regulation processes (Lindenberg 2013). Major advantage of the underlying goal-framing theory is that it provides a systematic inclusion of the respective time perspective of self-regulation, when introducing a hedonic goal-frame as the most basic goal frame with a very short time horizon and oriented towards what affects one's mood. It is distinguished from a gain goal-frame, which is oriented towards the maintenance or improvement of one's resources and has a middle- or long-term time horizon, and from a normative goal-frame, which regulates social group membership and has a long-term time horizon, both representing the two (former) dimensions of the 
production of physical and social well-being, as developed in the theory of social production functions. The relevance of these new developments in goal-framing theory for the extended VOC-approach is two-fold:

- First, it relates goal-related self-regulation processes to evidence based theories of social cognition, which have demonstrated that efficiency in the pursuit of goals is not limited to a "reflective-calculating"-mode of decision making, but is inherent also in highly automatized social-cognitive processes (Bargh et al. 2001, 2012). Self-regulation is then conceptualized as coordination of the overarching goals and the varying salience of secondary production factors in specific decision making situations - instead of a simple mode-“switch”.

- Second, it provides a theoretical foundation for the variations in the time horizon of having children in the social production of welfare (Graph 3) and relates it to evolutionary arguments, according to which the goal-frame with the shortest time horizon is the strongest, whereas the normative goal-frame with its longest time horizon is the weakest and depends on external support, such as institutionalization and moralization, (Lindenberg 2013: 85) - which is extremely important for policy implications of VOC.

Differences in the time horizon of the goal-frames may also provide new ideas for the explanation of new phenomena, so far not covered by the VOC-approach, as, for example, the timing and spacing of births in the life course. Self-regulation of the respective goal-frames for the production of welfare operates across all life domains of the individual. These life domains provide opportunities for the production of wellbeing, which may not always complement, but compete or substitute for each other. Following these arguments, early timing of child birth in the life course is most likely, if children are not substitutable in the gain-goal frame (in their work utility), or if alternatives in the hedonic goal-frame (stimulation and affection) do not exist. As parenthood is the product of already-gained stimulation and affection from partnership and marriage in modern societies, substitutive effects in the hedonic goal-frame systematically exist for potential parents. Parenthood itself becomes a complementary intermediate good within the same goal-frame, for which increasing incentives for postponement exist because the benefits are related to the long-term horizon of the normative goal-frame (dialogical interaction).

Future directions for improvement in research should consider that all previous studies used one informant only in each family, and were based on cross-sectional data, albeit from a variety of countries with substantial cultural and economic differences. Thus, the empirical connection between VOC and fertility might appear to be weaker than it really is, because in most cases, VOC information was gathered post hoc, either 
during or after completion of the fertility career. No empirical results are currently available regarding the emergence of VOC during the early life course or regarding the changes of VOC during the fertility career and in interaction with the offspring during the later life course, up to and including old age. Accordingly, no empirical evidence is so far available on the stability of utility expectations towards children. This is of crucial importance, however, since available studies assume that VOC is stable over the life course and thus see observed changes over historical time as related only to cohort differences (Thornton, Yang, and Fricke 1994).

Longitudinal data can provide empirical evidence on the emergence of VOC and its development over the life course, including the transition to parenthood. Moreover, currently available data are based on interviews with women only; mothers, in most cases. But VOC may vary systematically between potential fathers and mothers, based both on the institutional regulation of the kinship system and differences in the opportunity structures for husbands and wives.

Since fertility outcomes may be conceptualized as a joint product and a result of the couple's negotiations and decision making, based on individual resources and welfare production strategies, coupled information is needed at the very least. Even more useful are designs that study couples' decision making as embedded in a network structure, both as a source of information for the efficient pursuit of welfare production and as a source of social esteem and social control.

Finally, the extended VOC approach combines theoretical considerations and research efforts to reveal the conditions under which children are a non-substitutable intermediate good for parents' welfare production and under which conditions one's own children may be substituted by other kinds of social relationships or institutional regulations. Since stimulation and affection have become the most salient VOC in affluent societies, a research program is urgently needed that looks at substitution of these two instrumental goals by other activities and social relationships such as leisure time activities, informal group memberships, work relations, and partnership. The better understanding of competition, complementation, and substitution for parenthood with other modes of welfare production - and the extent to which these modes are mutually adaptive - is a necessary part of a comprehensive fertility theory.

In this perspective, the extended VOC-approach is well suited for the explanation of differences in fertility and intergenerational relationships, based on individual choices in the life course according to the (vastly varying) respective opportunity structures for the goal-framed production of physical and social welfare. According to the criterion of methodological individualism, it also fulfills the requirements for methodologically complete explanations, as it provides the necessary bridging assumptions between (macro-social) contexts and individual choices. Much less developed is the modeling of aggregated individual choices to macro-social outcomes, such as long-term trends in 
fertility rates on national levels, the institutionalization of fertility regimes, or social change in the division of publicly and privately organized intergenerational solidarity. In other words, it is still a long way to go from the attempts of micro-foundation of fertility behavior to the explanation of important macro-phenomena, such as the "second demographic transition", with its observation of the world-wide diffusion and spread of fertility well below replacement level (Lesthaeghe 2010), or why such diffusion processes develop at different pace in neighboring areas (Lesthaeghe and Neels 2002). However, as the necessary data for the comprehensive empirical testing of methodologically complete explanations of such diffusion processes are typically not available, they will have to rely on bridging assumptions, being tested and validated in studies, which relate (changes in) social contexts to individual choices.

At present, it seems that the theoretical arguments related to the VOC approach are more advanced than are the empirical methods and data for comprehensive testing. A promising outlook may be the German Panel Study on Intimate Relationships and Family Dynamics (pairfam) (Huinink et al. 2011; Keller and Nauck 2013), which will, once its panel structure is fully established, provide a data set that fulfills all the necessary requirements for use in testing the VOC approach: a longitudinal design that generates coupled data within a network structure in which parenthood is set against possible alternatives for welfare production.

\section{Acknowledgements}

A draft of this paper was presented at the conference "Theoretical Foundations for the Analysis of Fertility” in Lausanne, October 14-16, 2010, organized by Johannes Huinink and Martin Kohli. The final version was prepared during a stay as a visiting scholar at the California Center of Population Research of the University of California at Los Angeles. I thank three anonymous reviewers and Johannes Huinink for their constructive criticism and helpful comments. 


\section{References}

Albert, I., Trommsdorff, G., and Mishra, R. (2007). Parenting and adolescent attachment in India and Germany. In: Zheng, G., Leung, K., and Adair, J.G. (eds.). Perspectives and Progress in Contemporary Cross-cultural Psychology. Beijing, PR of China: China Light Industry Press.

Arnold, F., Bulatao, R.A., Buripakdi, C., Chung, B.J., Fawcett, J.T., Iritani, T., Lee, S.J., and Wu, T.S. (1975). The Value of Children: A Cross-National Study. Honululu: East-West Center.

Arnold, F. and Fawcett, J.T. (1975). The Value of Children: A Cross-National Study. Honululu: East-West Center.

Bargh, J.A., Gollwitzer, P.M., Lee-Chai, A., Barndollar, K., and Trötschel, R. (2001). The automated will: Nonconscious activation and pursuit of behavioral goals. Journal of Personality and Social Psychology 81(6): 1014-1027. doi:10.1037/0022-3514.81.6.1014.

Bargh, J.A., Schwader, K.L., Hailey, S.E., Dyer, R.L., and Boothby, E.J. (2012). Automaticity in social-cognitive processes. Trends in Cognitive Sciences 16(12): 593-605. doi:10.1016/j.tics.2012.10.002.

Becker, G.S. (1960). An Economic Analysis of Fertility. In: National Bureau Committee for Economic Research (ed.). Demographic and Economic Change in Developed Countries. Princeton: Princeton University Press: 209-231.

Becker, G.S. (1976). The Economic Approach to Human Behavior. Chicago: University of Chicago Press.

Bengtson, V.L. (2001). Beyond the Nuclear Family: The Increasing Importance of Multigenerational Bonds. Journal of Marriage and Family 63(1): 1-16. doi:10.1111/j.1741-3737.2001.00001.x.

Bengtson, V.L. and Roberts, R.E.L. (1991). Intergenerational Solidarity in Aging Families: An Example of Formal Theory Construction. Journal of Marriage and Family 53(4): 856-870. doi:10.2307/352993.

Braun, N. (2000). Ökonomische Theorien in der Bevölkerungswissenschaft. In: Mueller, U., Nauck, B., and Diekmann, A. (eds.). Handbuch der Demographie-Modelle und Methoden. Berlin: Springer Berlin Heidelberg: 298-338. doi:10.1007/ 978-3-642-57097-1_6. 
Bühler, C. (2004). Die Nutzung sozialer Netzwerke in unsicheren Situationen: Entscheidungen über Fertilität und Familienplanung in Kenia. In: Diekmann, A. and Voss, T. (eds.). Rational-Choice-Theorie in den Sozialwissenschaften: Anwendungen und Probleme. München: Oldenbourg: 309-330.

Bulatao, R.A. (1975). The Value of Children: A Cross-national Study. Philippines . Honululu: East-West Center.

Buripakdi, C. (1977). The Value of Children: Thailand . Honolulu: East-West-Center.

Coleman, J.S. (1990). Foundations of Social Theory. Cambridge: Harvard University Press.

Darroch, R.K., Meyer, P.A., and Singarimbun, M. (1981). Two are not enough: the value of children to Javanese and Sundanese parents. Honolulu: East-West Center.

Diefenbach, H. (2005). Die Rationalität von Kinderwünschen und reproduktivem Verhalten. Einige Anmerkungen zur konzeptionellen Weiterentwicklung des "value-of-children"-Modells. In: Steinbach, A. (ed.). Generatives Verhalten und Generationenbeziehungen: Festschrift für Bernhard Nauck zum 60. Geburtstag. Wiesbaden: VS Verlag für Sozialwissenschaften: 111-129. doi:10.1007/ 978-3-322-80641-3_7.

Easterlin, R.A. (1968). Population, Labor Force and Long Swings in Economic Growth. New York: Columbia University Press.

Esser, H. (1993). Soziologie: allgemeine Grundlagen. Frankfurt: Campus-Verlag.

Esser, H. (2002). Soziologie: Sinn und Kultur. Frankfurt: Campus-Verlag.

Esser, H. (2004). Wertrationalität. In: Diekmann, A. and Voss, T. (eds.). Rational-Choice-Theorie in den Sozialwissenschaften: Anwendungen und Probleme. München: Oldenbourg: 99-112.

Fawcett, J.T. (1972). The Satisfaction and Costs of Children: Theories, Concepts, Methods. Honululu: East-West Center.

Fawcett, J.T. (1973). Psychological Perspectives on Population. New York: Basic Books.

Fawcett, J.T. (1988). The Value of Children and the Transition to Parenthood. Marriage \& Family Review 12(3-4): 11-34. doi:10.1300/J002v12n03_03.

Friedman, D., Hechter, M., and Kanazawa, S. (1994). A theory of the value of children. Demography 31(3): 375-401. doi:10.2307/2061749. 
Hechter, M., Kim, H., and Baer, J. (2005). Prediction Versus Explanation in the Measurement of Values. European Sociological Review 21(2): 91-108. doi:10.1093/esr/jci006.

Hoffman, L.W. (1987). The Value of Children to Parents and Child Rearing Patterns. In: Kagitcibasi, C. (ed.). Growth and Progress in Cross-cultural Psychology. Berwyn/Lisse: Taylor \& Francis: 159-170.

Hoffman, L.W. and Hoffman, M.L. (1973). The Value of Children to Parents. In: Fawcett, J.T. (ed.). Psychological perspectives on population. New York: Basic Books: 19-76.

Huinink, J. (1995). Warum noch Familie?: zur Attraktivität von Partnerschaft und Elternschaft in unserer Gesellschaft. Frankfurt: Campus.

Huinink, J., Brüderl, J., Nauck, B., Walper, S., Castiglioni, L., and Feldhaus, M. (2011). Panel Analysis of Intimate Relationships and Family Dynamics (pairfam). Conceptual framework and design. Zeitschrift für Familienforschung 23(1): 77-101.

Iritani, T. (1977). The Value of Children: Japan. Honolulu: East-West-Center.

Kagitcibasi, C. (1982a). The Changing Value of Children in Turkey. Honolulu: East-West-Center.

Kagitcibasi, C. (1982b). Sex Roles, Values of Children, and Fertility. In: Kagitcibasi, C. (ed.). Sex roles, family \& community in Turkey. Bloomington: Indiana University Press: $151-180$.

Kagitcibasi, C. (1985). Intra-Family Interaction and a Model of Family Change. In: Erder, T. (ed.). Family in Turkish society. Ankara: MAYA: 149-165.

Kagitcibasi, C. (2007). Family and Human Development Across Cultures: A View From the Other Side. Mahwah: Erlbaum.

Kagitcibasi, C. and Ataca, B. (2005). Value of Children and Family Change: A Three-Decade Portrait From Turkey. Applied Psychology 54(3): 317-337. doi:10.1111/j.1464-0597.2005.00213.x.

Kagitcibasi, C., Ataca, B., and Diri, A. (2010). Intergenerational Relationships in the Family: Ethnic, Socioeconomic, and Country Variations in Germany, Israel, Palestine, and Turkey. Journal of Cross-Cultural Psychology 41(5-6): 652-670. doi:10.1177/0022022110372193. 
Keller, S. and Nauck, B. (2013). The German Family Panel (pairfam). Research Potential and First Results of a Multi-Disciplinary Longitudinal Study on Partnership and Family Dynamics in Germany. Analyse und Kritik 35(2): 321-339.

Kim, U. and Park, Y.S. (2005). Family, Parent-Child Relationships, Fertility Rates, and Value of Children in Korea: Indigenous, Psychological, and Cultural Analysis. In: Trommsdorff, G. and Nauck, B. (eds.). The Value of Children in Cross-cultural Perspective: Case Studies from Eight Societies. Lengerich: Pabst: 209-237.

Klaus, D. (2008). Sozialer Wandel und Geburtenrückgang in der Türkei: Der "Wert von Kindern" als Bindeglied auf der Akteursebene. Wiesbaden: VS Verlag für Sozialwissenschaften.

Klaus, D. (2010). Changing Value of Children and Fertility Transition in Turkey. Journal of Comparative Family Studies 41(5): 799-815.

Klaus, D., Nauck, B., and Klein, T. (2005). Families and the Value of Children in Germany. In: Trommsdorff, G. and Nauck, B. (eds.). The Value of Children in Cross-cultural Perspective: Case Studies from Eight Societies. Lengerich: Pabst: 17-41.

Klaus, D. and Suckow, J. (2005). Der Wert von Kindern und sein langer Schatten. Eine kritische Würdigung der VOC-Forschung. In: Steinbach, A. (ed.). Generatives Verhalten und Generationenbeziehungen: Festschrift für Bernhard Nauck zum 60. Geburtstag. Wiesbaden: VS Verlag für Sozialwissenschaften: 85-109. doi:10.1007/978-3-322-80641-3_6.

Klaus, D., Suckow, J., and Nauck, B. (2007). The Value of Children in Palestine and Turkey: Differences and the Consequences for Fertility. Current Sociology 55(4): 527-544. doi:10.1177/0011392107077637.

Klaus, D., Suckow, J., and Soloveva, S. (2009). Generatives Verhalten und der Wert von Kindern in Ostdeutschland und Russland. Zeitschrift für Soziologie der Erziehung und Sozialisation 29: 10-28.

Kroneberg, C. (2005). Die Definition der Situation und die variable Rationalität der Akteure: ein allgemeines Modell des Handelns auf der Basis von Hartmut Essers Frame-Selektionstheorie. Zeitschrift für Soziologie 34(5): 344-363.

Kroneberg, C. (2011). Die Erklärung Sozialen Handelns: Grundlagen und Anwendung Einer Integrativen Theorie. Wiesbaden: VS Verlag für Sozialwissenschaften GmbH. doi:10.1007/978-3-531-93144-9. 
Lee, S.J. (1975). The Value of Children. A cross-national study: Korea. Honolulu: East-West-Center.

Leibenstein, H. (1957). Eceonomic Backwardness and Economic Growth. Studies in the Theory of Economic Development. New York: Wiley.

Leibenstein, H. (1974). An Interpretation of the Economic Theory of Fertility: Promising Path or Blind Alley? Journal of Economic Literature 12(2): 457-479.

Lesthaeghe, R. (2010). The Unfolding Story of the Second Demographic Transition. Population and Development Review 36(2): 211-251. doi:10.1111/j.1728-4457. 2010.00328.x.

Lesthaeghe, R. and Neels, K. (2002). From the First to the Second Demographic Transition: An Interpretation of the Spatial Continuity of Demographic Innovation in France, Belgium and Switzerland. European Journal of Population 18(4): 325-360. doi:10.1023/A:1021125800070.

Lesthaeghe, R. and Surkyn, J. (1988). Cultural Dynamics and Economic Theories of Fertility Change. Population and Development Review 14(1): 1-45. doi:10.2307/ 1972499.

Lindenberg, S. (1991). Social Approval, Fertility and Female Labour Market. In: Siegers, J.J., Jong-Gierveld, J., and Imhoff, E. (eds.). Female Labour Market Behaviour and Fertility. Berlin: Springer: 32-58. doi:10.1007/978-3-642-76550-6_3.

Lindenberg, S. (1996). Continuities in the theory of social production functions. In: Ganzeboom, H.B. and Lindenberg, S. (eds.). Verklarende sociologie: opstellen voor Reinhard Wippler. Amsterdam: Thesis Publishers.

Lindenberg, S. (2013). Social Rationality, Self-Regulation, and Well-Being: The Regulatory Significance of Needs, Goals, and the Self. In: Wittek, R., Snijders, T., and Nee, V. (eds.). The Handbook of Rational Choice Social Research. Stanford : Stanford University Press.

Mares, P. and Mozny, I. (2005). The Czech Family, Reproductive Behavior, and the Value of Children in the Czech Republic. In: Trommsdorff, G. and Nauck, B. (eds.). The Value of Children in Cross-cultural Perspective: Case Studies from Eight Societies. Lengerich: Pabst: 67-90.

Maslow, A.H. (1954). Motivation and Personality. New York: Harper \& Row.

Mayer, B. (2009). Adolescents Family Models: A Cross-Cultural Study [Dissertation]. Konstanz: Universität Konstanz. 
Mayer, B., Albert, I., Trommsdorff, G., and Schwarz, B. (2005). Value of Children in Germany: Dimensions, Comparison of Generations, and Relevance for Parenting. In: Trommsdorff, G. and Nauck, B. (eds.). The Value of Children in Cross-cultural Perspective: Case Studies from Eight Societies. Lengerich: Pabst: 43-65.

Mayer, B. and Trommsdorff, G. (2010). Adolescents' Value of Children and Their Intentions to Have Children: A Cross-Cultural and Multilevel Analysis. Journal of Cross-Cultural Psychology 41(5-6): 671-689. doi:10.1177/0022022110372 195.

Nauck, B. (1989). Intergenerational relationships in families from Turkey and Germany: An extension of the 'value of children' approach to educational attitudes and socialization practices. European Sociological Review 5(3): 251-274.

Nauck, B. (1997). Sozialer Wandel, Migration und Familienbildung bei türkischen Frauen. In: Nauck, B. and Schönpflug, U. (eds.). Familien in verschiedenen Kulturen. Stuttgart: Enke: 162-199.

Nauck, B. (2001). Der Wert von Kindern für ihre Eltern. Kölner Zeitschrift für Soziologie und Sozialpsychologie 53(3): 407-435. doi:10.1007/s11577-001-0073-7.

Nauck, B. (2005). Changing Value of Children: An Action Theory of Fertility Behavior and Intergenerational Relationships in Cross-Cultural Comparison. In: Friedlmeier, W., Chakkarath, P., and Schwarz, B. (eds.). Culture and Human Development: The Importance of Cross-Cultural Research for the Social Sciences. Hove: Psychology Press: 183-202.

Nauck, B. (2006). Value of Children and Fertility Strategies in Cross-cultural Comparison. Ideal Family Size and Targeted Fertility in Eleven Societies. In: Gomes, C. (ed.). Social Development and Family Changes. Newcastle: Cambridge Scholars Press: 300-344.

Nauck, B. (2007a). Familiensystem und Kultur. In: Trommsdorff, G. and Kornadt, H.J. (eds.). Theorien und Methoden der kulturvergleichenden Psychologie. Göttingen: Hogrefe: 407-486.

Nauck, B. (2007b). Value of Children and the Framing of Fertility: Results from a Cross-cultural Comparative Survey in 10 Societies. European Sociological Review 23(5): 615-629. doi:10.1093/esr/jcm028.

Nauck, B. (2009). Patterns of Exchange in Kinship Systems in Germany, Russia, and the People's Republic of China. Journal of Comparative Family Studies 40(2): 255-278. 
Nauck, B. (2010a). Fertilitätsstrategien im interkulturellen Vergleich: Value of Children, ideale und angestrebte Kinderzahl in zwölf Ländern. In: Mayer, B. and Kornadt, H.J. (eds.). Psychologie - Kultur - Gesellschaft. VS Verlag für Sozialwissenschaften: 213-238. doi:10.1007/978-3-531-92212-6_9.

Nauck, B. (2010b). Intergenerational Relationships and Female Inheritance Expectations: Comparative Results From Eight Societies in Asia, Europe, and North America. Journal of Cross-Cultural Psychology 41(5-6): 690-705. doi:10.1177/0022022110375161.

Nauck, B. (2014a). Value of children and fertility: Results from a cross-cultural comparative survey in eighteen areas in Asia, Africa, Europe and America. Advances in Life Course Research (in press). doi:10.1016/j.alcr.2014.01.004.

Nauck, B. (2014b). Cross-cultural Variations in Intergenerational Ambivalence. Affection and Conflict in the Relationship of Women with their Parents in Sixteen Areas in Asia, Africa, Europe and America. Comparative Population Studies (in press).

Nauck, B. and Arránz Becker, O. (2013). Institutional Regulations and the Kinship Solidarity of Women-Results from 13 Areas in Asia, Africa, Europe, and North America. European Sociological Review 29(3): 580-592. doi:10.1093/esr/jcr110.

Nauck, B. and Klaus, D. (2007). The Varying Value of Children: Empirical Results from Eleven Societies in Asia, Africa and Europe. Current Sociology 55(4): 487-503. doi:10.1177/0011392107077634.

Notestein, F.W. (1945). Population - the long view. In: Schultz, T.W. (ed.). Food for the world. Chicago: University of Chicago Press.

Robinson, W.C. (1997). The Economic Theory of Fertility Over Three Decades. Population Studies 51(1): 63-74. doi:10.1080/0032472031000149736.

Rudolf, Carolin. (2010). Der Geburtenrückgang in Indonesien. Eine empirische Analyse anhand des "Value of Children"-Ansatzes. Wiesbaden: VS Verlag für Sozialwissenschaften. doi:10.1007/978-3-531-92537-0.

Schwarz, B. (2010). Generationenbeziehungen im Kulturvergleich. In: Mayer, B. and Kornadt, H.J. (eds.). Psychologie-Kultur-Gesellschaft. VS Verlag für Sozialwissenschaften: 141-159. doi:10.1007/978-3-531-92212-6_6.

Schwarz, B., Albert, I., Trommsdorff, G., Gang, Z., Shaohua, S., and Nelwan, P.R. (2010). Intergenerational Support and Life Satisfaction: A Comparison of 
Chinese, Indonesian, and German Elderly Mothers. Journal of Cross-Cultural Psychology 41(5-6): 706-722. doi:10.1177/0022022110372197.

Schwarz, B., Schäfermeister, E., and Trommsdorff, G. (2005). Relations between Value Orientation, Child-Rearing Goals, and Parenting: A Comparison of German and South Korean Mothers. In: Friedlmeier, W., Chakkarath, P., and Schwarz, B. (eds.). Culture and Human Development: The Importance of Cross-Cultural Research for the Social Sciences. Hove: Psychology Press: 203-230.

Schwarz, B., Trommsdorff, G., Albert, I., and Mayer, B. (2005). Adult Parent-Child Relationships: Relationship Quality, Support, and Reciprocity. Applied Psychology 54(3): 396-417. doi:10.1111/j.1464-0597.2005.00217.x.

Schwarz, B., Trommsdorff, G., Gang, Z., and Shaohua, S. (2010). Reciprocity in Intergenerational Support: A Comparison of Chinese and German Adult Daughters. Journal of Family Issues 31(2): 234-256. doi:10.1177/0192513x093 47991.

Schwarz, B., Trommsdorff, G., Kim, U., and Park, Y.S. (2006). Intergenerational Support: Psychological and Cultural Analyses of Korean and German Women. Current Sociology 54(2): 315-340. doi:10.1177/0011392106056748.

Steinbach, A. (2008). Intergenerational Solidarity and Ambivalence: Types of Relationships in German Families. Journal of Comparative Family Studies 39(1): 115-127.

Suckow, J. (2005). The Value of Children among Jews and Muslims in Israel: Methods and Results from the VOC-Field Study. In: Trommsdorff, G. and Nauck, B. (eds.). The Value of Children in Cross-cultural Perspective: Case Studies from Eight Societies. Lengerich: Pabst: 121-170.

Suckow, J. (2007). The dependence of the value of children on socio-structural characteristics: The case of Israel and Palestine. In: Zheng, G., Leung, K., and Adair, J.G. (eds.). Perspectives and Progress in Contemporary Cross-cultural Psychology. Beijing, PR of China: China Light Industry Press: 119-128.

Suckow, J. (2008). Fertilität in Israel und Palästina: Ein Erklärungsbeitrag der Value-of-Children-Forschung. Würzburg: Ergon Verlag.

Thomson, E. (2001). Value of Children. In: Smelser, N.J. and Baltes, P.B. (eds.). International Encyclopedia of the Social \& Behavioral Sciences. Oxford: Pergamon: 1725-1729. doi:10.1016/B0-08-043076-7/02147-1. 
Thornton, A., Yang, L.S., and Fricke, T. (1994). Weakening the Linkage between the Ancestors, the Living, and Future Generations. In: Thornton, A. and Lin, H.S. (eds.). Social Change and the Family in Taiwan. Chicago: University of Chicago Press: 359-395.

Trommsdorff, G., Kim, U., and Nauck, B. (2005). Factors Influencing Value of Children and Intergenerational Relations in Times of Social Change: Analyses From Psychological and Socio-Cultural Perspectives: Introduction to the Special Issue. Applied Psychology 54(3): 313-316. doi:10.1111/j.1464-0597.2005.00212.x.

Trommsdorff, G. and Meyer, B. (2012). A Cross-Cultural Study of Intergenerational Relations: The Role of Socioeconomic Factors, Values, and Relationship Quality in Intergenerational Support. In: Bertram, H. and Ehlert, N. (eds.). Family, Ties and Care: Family Transformation in a Plural Modernity. Opladen: Barbara Budrich Publishers: 315-342.

Trommsdorff, G. and Nauck, B. (eds.) (2005). The Value of Children in Cross-cultural Perspective: Case Studies from Eight Societies. Lengerich: Pabst.

Trommsdorff, G. and Nauck, B. (2010). Introduction to Special Section for Journal of Cross-Cultural Psychology: Value of Children: A Concept for Better Understanding Cross-Cultural Variations in Fertility Behavior and Intergenerational Relationships. Journal of Cross-Cultural Psychology 41(5-6): 637-651. doi:10.1177/0022022110373335.

Urdze, A. and Rerrich, M.S. (1981). Frauenalltag und Kinderwunsch: Motive von Müttern für oder gegen ein zweites Kind. Frankfurt: Campus-Verlag.

Van Ijzendoorn, M.H. and Sagi, A. (1999). Cross-cultural Patterns of Attachment. Universal and Contextual Dimensions. In: Cassidy, J. and Shaver, P.R. (eds.). Handbook of Attachment, Second Edition: Theory, Research, and Clinical Applications. London: Guilford Publications: 713-734.

Wu, T.S. (1977). The value of children: Taiwan. Honolulu: East-West-Center.

Zelizer, V.A. (1994). Pricing the Priceless Child: The Changing Social Value of Children. Princeton: Princeton University Press.

Zheng, G., Shi, S., and Tang, H. (2005). Population Development and the Value of Children in the People's Republic of China. In: Trommsdorff, G. and Nauck, B. (eds.). The Value of Children in Cross-cultural Perspective: Case Studies from Eight Societies. Lengerich: Pabst: 239-281. 